\title{
Continuous Improvement and Business Sustainability in Companies of an Emerging Market: Empirical Analysis
}

\author{
César A. Bernal-Torres ${ }^{1}$ (D), Luis Paipa-Galeano ${ }^{2 *}$ (D), Yavar Jarrah-Nezhad ${ }^{2}$ (ID, \\ Luis M. Agudelo-Otálora² iD, Javier Millán² (iD \\ ${ }^{1}$ International School of Economics and Business Administration, Universidad de La Sabana (Colombia) \\ ${ }^{2}$ Faculty of Engineering, Universidad de La Sabana (Colombia) \\ cesar.bernal@unisabana.edu.co, ,Correspondingauthor:luispg@unisabana.edu.co,yavar.jarrab@unisabana.edu.co, \\ mauricio.agudelo@unisabana.edu.co,javier.millan@unisabana.edu.co
}

Received: June 2021

Accepted: August 2021

\section{Abstract:}

Purpose: The article analyses the impact of continuous improvement (system and teams) on business sustainability dimensions (social, environmental, operational, and financial) as a competitive strategy to create value for all stakeholders in emerging economy context.

Design/methodology/approach: The data collected is from 120 companies of different sizes and 13 different industrial sectors such as food, energy, health, financial services, and logistics in Colombia. The design of multivariate logistic regression is to identify the critical aspects of the continuous improvement practices that significantly affect the dimensions of business sustainability.

Findings: The analysis shows that from continuous improvement aspects (system and teams), employee involvement, human talent maintenance, training, and evaluation accompanied by feedback impact business sustainability. These elements impact financial and operational dimensions significantly but in the environmental and social aspects with less intensity.

Research limitations/implications: Research is limited to the general sustainability analysis applying resource-based strategy in Colombia.

Practical implications: Generate overall awareness of the importance of the equilibrium of sustainability dimensions in strategic planning and implementation in emerging economies.

Originality/value: This work applies an empirical study to establish the impact of continuous improvement (system and teams) on each of the business sustainability dimensions (social, environmental, operational, and financial) in companies of emerging economies.

Keywords: business sustainability, continuous improvement, logistic regression model, work teams

\section{To cite this article:}

Bernal-Torres, C.A., Paipa-Galeano, L., Jarrah-Nezhad, Y., Agudelo-Otálora, L.M., \& Millán, J. (2021). Continuous improvement and business sustainability in companies of an emerging market: Empirical analysis. Journal of Industrial Engineering and Management, 14(4), 771-787. https://doi.org/10.3926/jiem.3610 


\section{Introduction}

There is a global accord on the necessity of contribution towards UN 17 sustainable development goals (SDGs). Countries and companies adopt strategies to achieve these goals. However, the lack of research and practice with a comprehensive and holistic vision of sustainable development and business sustainability itself leaves a gap between the assigned goals and the current state especially in emerging markets (Silvestre \& Tî̀rcă, 2019). Additionally, at present, in society there is no consensus on the very meaning of sustainability (Landrum, 2018), neither on the indicators that measure the harmonious performance between the environmental, social and economic aspects (Medne \& Lapina, 2019). Situation is more complex in the context of emerging economies due to the presence of factors such as corruption, lack of infrastructure, social problems, informality, and the culture of emphasis on economic benefits (Mani, Gunasekaran \& Delgado, 2018).

Specifically, organisations are under enormous pressure to improve productivity and remain competitive in the global market and an increased responsibility awareness towards society and environmental issues (Taddeo, Simboli, Di Vincenzo \& Ioppolo, 2019; Muñoz-Villamizar, Santos, Viles \& Ormazábal, 2018). In response to these challenges, companies focus their activities on business sustainability (BS) that is defined as the capacity to generate added value in the short, medium, and long term for their different stakeholders, minimising the negative impact on society and the environment (Abbas, 2020; Medne \& Lapina, 2019). There are different approaches to achieve BS. One solution is Continuous Improvement (CI) which is considered as one of the core strategies to achieve manufacturing excellence (Abbas, 2020; Jurburg, Viles, Tanco \& Mateo, 2018; Pojasek, 2007). The crucial elements of CI implementation are improvement system (structure) and active employee participation through work teams (García-Arca \& Prado-Prado, 2011).

In effect, several studies evaluated the relationship between specific methodologies of CI and BS. For instance, Mårtensson, Snyder and Ingelsson (2019) advise managers to have a better comprehension of the relation between Lean implementation and BS to achieve high performance. More concretely, Vicente, Alves, Carvalho and Costa (2015) analysed employee involvement and collaboration concerning BS and revealed that the problems are related to salaries, lack of information and no-open conversation with managers that are on top of the business hierarchy. Meza-Ruiz, Rocha-Lona, Soto-Flores, Garza-Reyes, Kumar \& López-Torres (2019) indicate that strategies such as self-assessment, benchmarking, corporate reporting, strategic planning, and systematic training, are significant facilitators of BS.

Past theoretical and practical research about CI and BS are mainly in advanced economies, and there is a shortage of research in emerging markets. To fill this gap, 120 company managers from different sized Colombian companies and economic sectors took part in a survey consisting of three parts (CI systems and work teams, and organisational performance in terms of BS). The data processing applies descriptive statistics and multivariate logistic regression. The goal of the article is to analyse the impact of continuous improvement (system and teams) on business sustainability dimensions (social, environmental, operational, and financial) as a competitive strategy to create value for all stakeholders in emerging economy context.

The process and phases are explained in this paper as follows. Section 2 provides a literature review, and section 3 presents the methodology. Parts 4 and 5 provide the survey results and discussions. Finally, the last part outlines the conclusion and concluding remarks.

\section{Literature Review}

\subsection{Continuous Improvement: System and Work Teams}

The term CI derives from the Japanese word Kaizen that was developed by Masaaki Imai (Sanchez \& Blanco, 2014). Scholars define CI as a planned, organised, and systematic approach to improving organisational performance (González-Aleu \& Van Aken, 2016; Granerud \& Rocha, 2011). Therefore, CI is associated with comprehensive methodologies (lean production; six sigma; quality control circles; total quality management and employee idea systems) that utilise a dedicated work team to improve a process or system typically with minimal capital investment and over a relatively short period. 
The crucial elements of CI implementation are improvement system and active employee participation through work teams (Garcia-Arca \& Prado-Prado, 2011). The improvement system is applying a formalised programme that establishes a set of steps to achieve a general or specific purpose (Jaca, Suárez-Barraza, Viles-Díez, Mateo-Dueñas \& Santos-García, 2011). According to Formento, Chiodi, Cusolito, Altube and Gatti (2013), the improvement system generates the support structure that allows the creation of the routines suggested by Bessant, Caffyn and Gallagher (2001) in improvement stages of their evolutionary model. A work team is a small group of employees led by a coordinator. They meet periodically to analyse and resolve a specific problem or carry out improvements in the company. In general, the group dissolves when the problem is solved (García-Arca \& Prado-Prado 2011).

The successful implementation of CI depends much on employee involvement at all hierarchical levels of an organisation and the implemented systems. The prior research in advanced economies identified the critical factors for developing personnel participation as follows: top management commitment; personnel commitment; involvement based on work teams; availability of key performance indicators for monitoring participation activities; an organisational structure for supporting participation activities; methodology for managing personnel proposals; continuous communication in participation activities; middle manager commitment; unions commitment; specific training for developing participation system both individually and as a team; availability of resources; adoption of a recognition/reward system for participants (Marín-García \& Bautista-Poveda, 2010; García-Arca \& Prado-Prado, 2011; Marin-Garcia \& Bonavia, 2014).

\subsection{Business Sustainability (BS)}

BS initially was known as the social responsibilities of business coined by Howard Bowen (Chang, Zuo, Zhao, Zillante, Gan \& Soebarto, 2017). The term evolved into corporate social responsibility, and the organisational field increasingly applies the concept of sustainable development (Corrales-Estrada, Gómez-Santos, Bernal-Torres \& Rodriguez-López, 2021; Steurer, 2010). Currently, there is no universal definition of BS (Chang et al., 2017). However, different approaches highlight the importance of satisfying the needs of stakeholders in a social, environmental, and economic balance, also known as triple bottom line (TBL). This concept is related to meet the necessities in the short, medium, and long term without compromising the ability of future generations to meet their needs (Liu, Wu, Zhong \& Liu, 2020; Rezaee, 2016). According to BS, "social" refers to the impact of business activity on the workforce and surrounding communities, "environmental" is to maintain consumption below nature's regeneration ability, and "economic" is the persistent financial return (Vicente et al., 2015; Medne \& Lapina, 2019).

However, a literature review by Pinto, Venturini, Digiesi, Facchini and Oliveira Neto (2020) suggests a need for more wholistic definition of BS which they refer to as strong or solid sustainability. Instead of searching for the balance between economic, social, and environmental aspects strong sustainability consider the environment as fundamental to human well-being and economic growth. This is because limitation and scarcity occur exclusively in natural resources, while manufactured products are reproducible and social demands change with generations (Oliveira Neto, Pinto, Amorim, Giannetti \& Almeida, 2018; Martins, 2016).

The prior research indicates that environment continues to deteriorate no matter how companies increasingly adopt sustainability standards. The lack of a stronger concept based on concern for the environment in micro and macro level is the reason for this phenomenon (Dyllick \& Muff, 2016; Landrum, 2018).

In result, in this research the concept of BS refers to the application of effective process and resource management at the company level; the value addition to different stakeholders; participating in the market in medium and long term; striving for social development and the care of the environment while obtaining economic benefits for its investors (Liu et al., 2020; Medne \& Lapina, 2019).

In relation to indicators, Medne and Lapina (2019), indicated that there is a wide range of indicators to measure performance concerning sustainability. At present, the most used BS indicators are those related to the company's financial, operational or productivity performance in terms of resources; customer and employee satisfaction; social responsibility and environmental care. Recently, Mårtensson et al. (2019) include indicators such as ethics and transparency. The implication is that organisations need to evaluate their internal activity (financial and non- 
financial or operational), and indicators that assess the companies' relationship with society and the environment (Nigri \& Del Baldo, 2018).

Previous studies based on the TBL model considered the economic dimension as one concept; however, in business theory, the company's performance is usually measured in terms of financial and operational measures. The operational indicators include operating changes in the goods or services offered; improvement in the processes of business activity in relationships with customers, suppliers, and competitors; and the quality improvement of products or services (Liao, Chen \& Deng, 2010). The evaluation of financial results of the economic dimension is in terms of the increase in profits, market share, or sales volume (López, Hernández \& Marulanda, 2014). Sheth and Minha (2015) indicate that to guaranty commitment to BS, the companies should move from market, customer, and profit orientation to commitment to social and environmental issues.

For this reason, the present research disaggregates the financial and operational viewpoint to have a broader and more comprehensive vision of the BS components. As a result, for this research, the BS indicators include financial, operational, social and environmental activities.

\subsection{Relation of Continuous Improvement and Business Sustainability}

Scholars, in developed countries, highlight that quality systems, particularly the quality management certificates, are related to an excellent reputation for quality and BS and also, they indicate positive effects in financial indicators, such as ROA (return on assets) and Tobin's Q (Boulter, Bendel \& Dahlgaard, 2013). However, the failures of quality-awarded companies such as Nokia, Motorola and Kodak indicate that the certifications cannot guaranty the success of the company (Liu et al., 2020). Additionally, there is no evidence of the positive relationship between the CI practices and quality certificates (Sabella, Kashou \& Omran, 2014) and operational, environmental, and social performance (Treacy, Humphreys, McIvor \& Lo, 2019).

The main reason for the low impact of CI practices, and of certifications, is that organisations generally dedicate high priority towards achieving economic benefits while ignoring the importance of operational, social and environmental aspects (Fernando, Jabbour \& Wah, 2019; Neri, Cagno, Di Sebastiano \& Trianni, 2018).

The prior research highlights the importance of CI systems and work teams in BS. In terms of systems, according to Pojasek (2007), companies should use integrated management approaches such as CI to achieve their excellence and sustainability by creating value for their different stakeholders. Based on the structure design, companies develop the necessary capabilities, provide knowledge, skills, and appropriate mentality (Mohrman \& Worley, 2010). The design considers job enlargement, training, teamwork, and work team involvement (Longoni, Golini \& Cagliano, 2014; Daily, Bishop \& Massoud, 2012). In terms of the work team, the research indicates that it improves information flow and experience available; facilitates coordination and integration of efforts; avoids overlapping tasks; increases the effectiveness of innovative processes; allows employees to share problems and solutions with the managers (Conti, Angelis, Cooper, Faragher \& Gill, 2006). In this way, the adoption of work teams impacts each of BS dimensions positively (Schroeder \& Robinson, 2010).

\subsection{Continuous Improvement and Business Sustainability in Emerging Markets}

Emerging markets are characterised by highly turbulent business environments, with institutional gaps, lags in the application of science, technology and innovation generation, low productivity, and emphasis on the export of natural resource-based products with little added value (Gölgeci, Assadinia, Kuivalainen \& Larimo, 2019; Bortagaray \& de Montevideo, 2016). Also, they are dealing with traditional administrative structures and short-term organisational vision, with limited environmental culture and in many cases wage inequity, among other aspects, which are limiting the new corporate practices (Bernal, Amaya, Gaviria-Peñaranda \& Zwerg-Villegas, 2020).

Besides, the impact and interaction between BS dimensions in different contexts is still an area in dispute. According to Jayanti and Gowdab (2014), in emerging economies, there are conflicting interests between various aspects of sustainability. In result, the companies have difficulty in linking sustainability to innovation and operational efficiency; competitive advantage; reputation building; environmental impact assessment; differentiation; eco-design; and best human resource practices. 
According to Lacy and Hayward (2011), CEOs in emerging economies consider sustainability fundamental to their business success, even more than developed economies. Nevertheless, in their pursuit of integrated strategic planning and sustainability implementation face barriers such as complexity of strategy implementation across functions, conflicting strategic priorities, lack of recognition, different definitions of corporate social responsibility, difficulty in engaging with external groups, lack of acceptance of a link to value drivers. Additionally, Silvestre (2015) identifies four barriers specific to sustainable supply chains which are: corruption, lack of infrastructure, pressing social problems in urban areas and informality.

In terms of CI in emerging markets, Paipa-Galeano, Bernal-Torres, Otálora, Jarrah Nezhad and González-Blanco (2020), identified critical success factors for organisational performance. The factors are the availability of resources; management commitment; employee participation in improvement task identification; straightforward and realistic objectives; and, finally, the existence of a leader. The primary barriers are lack of alignment between organisational and continuous improvement objectives; lack of motivation in the work team; and resistance to change. Furthermore, Nguyen and Robinson (2015) identified substantial investment in human capital as a CI key success factor that provides managers and employees proper education and training and robust top-down management approach; and the successful CI practices in developed economies are not applicable in emerging markets.

Moreover, some studies have emphasised the relevance of internal social programs and the appropriate design of operational support (Hasle, Bojesen, Jensen \& Bramming, 2012). Concerning the social aspect, Mani et al. (2018) indicate that the problems depend on the unique context of each emerging economy, and the companies require different managerial approaches.

So, there is an increased interest in developing a comprehensive framework based on empirical evidence on the role of employees and organisational practices in achieving BS in emerging markets (Medne \& Lapina, 2019). However, little research has assessed the relation between operational practices and BS (del Brío, Fernandez \& Junquera, 2007). Another flaw is that the articles that have studied this link are mainly conceptual or based on case studies (Teixeira, Jabbour \& Jabbour, 2012). Very few studies focus on the specifics of emerging economies that indicates the lack of diversity in the authorship, company size and the location (Creasey, 2007) as most research on BS focuses on multinational companies or those in developed economies (García-Alcaraz, Flor-Montalvo, Avelar-Sosa, Sánchez-Ramírez \& Jiménez-Macias, 2019; Silvestre, 2015; Jayanti \& Gowda, 2014).

In conclusion, it is necessary to demonstrate the impact of CI systems and work teams on BS dimensions in the context of emerging economies.

\section{Methodology}

In the following sections presents the process of sample choice and their characteristics. In continuation, the discussion provides the research design process, including feature selection, survey design, and the characteristics of the instrument. The third subsection lays out the application of multivariate logistic regression analysis, the validation of internal consistency applying Cronbach's alpha. At last, Wald test results determine if an independent variable contributed towards the impact anticipated. Figure 1 shows the methodology phases for this research.

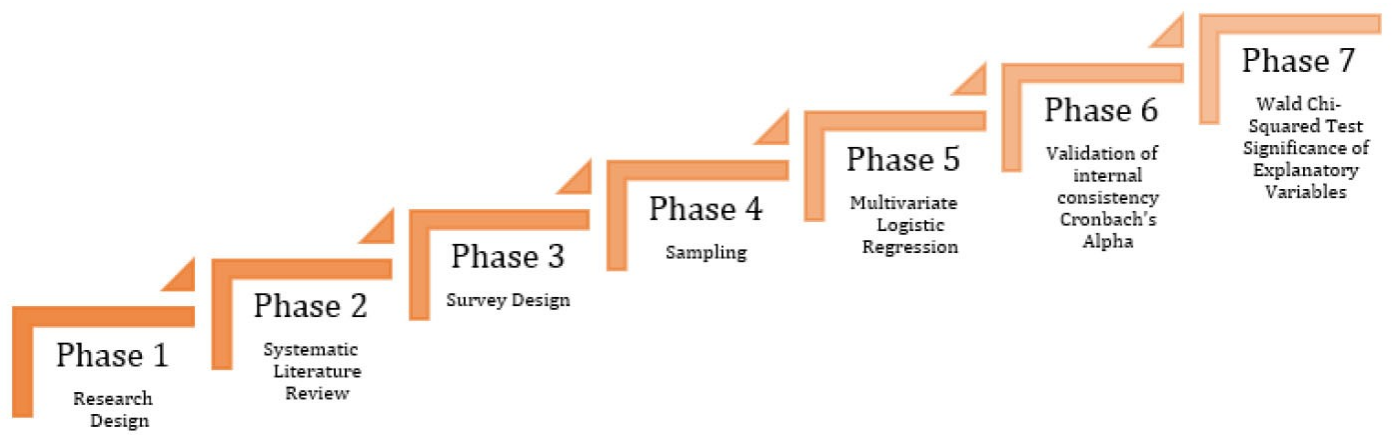

Figure 1. Methodology phases 


\subsection{Sample Size}

The data collection is from managers of companies of different sizes and sectors of economic activities with more than five years of market presence, and formal registration in the chamber of commerce. The companies must practice CI activities during the last three years. Simple random sampling determines the participating managers' sample size applying the following formula:

$$
n=\frac{Z_{\alpha / 2}^{2} * \sigma^{2}}{(e)^{2}}=\frac{1,96^{2} * 0,5^{2}}{0,1^{2}} \approx 96
$$

where:

$n=$ sample size to estimate.

$\mathrm{Z}_{\alpha / 2}=$ statistical confidence level $(95 \%)$

$\sigma^{2}=$ variance estimated $(10 \%)$

$e=$ estimation error

The minimum necessary sample size for this research is 96 . In compliance with this requirement, the CI processes department of 200 companies received the questions via email. From 134 surveys, 14 did not pass due to the lack of answers to survey questions. So, the study included only 120 (24 small, 30 medium, and 66 large companies).

\subsection{Survey Development}

The survey is designed based on the literature review and particularly CI indicators by Jaca et al. (2011), and sustainability indicators by Nigri and Baldo (2018) and Medne and Lapina (2019). The scholars classified the variables defined in the measurement instrument into three groups (86 items, 57 of which are in the Likert scale, and 29 are multiple choice):

- Improvement system dimensions (39 survey items) aimed to identify the state of the current support structure regarding CI.

- Work team dimension (31 survey items) aimed to identify the characteristics of the work team in the companies.

- The impact of improvement aimed to measure a company's key performance indicators (16 survey items) in the social, environmental, and economic (financial and operational) BS dimensions.

The internal consistency calculation includes only Likert-scale-type items (Welch \& Comer, 1988). Cronbach's alpha is 0.937 , which, according to (George \& Mallery, 2003), demonstrates excellent internal reliability.

\subsection{Data Analysis}

The results' analysis had two stages. The first stage describes the company's current support structure regarding CI and the work team. The second stage consisted of multivariate logistic regression analysis (MLRA) oriented towards evaluating the relationship between the improvement system, and work team regarding each of the BS dimensions. The study utilises MLRA due to the following attributes (Ranganathan, Pramesh \& Aggarwal, 2017):

- It allows the combination of different types of numerical and categorical variables.

- The probabilistic method allows for inferring results from the study population.

- Multivariate data analysis offers objective methods to reveal how many factors are necessary to describe a complex reality and determine its structure.

- The method constructs a forecast model of the response variable of interest.

The following regression formula was applied:

$$
P(Y=1)=\frac{1}{1+e^{-\left(\beta_{0}+\beta_{1} x_{1}+\beta_{2} x_{2}+\cdots+\beta_{k} x_{k}\right)}}
$$


where:

$P=$ probability of "success" if each independent explanatory variable $\mathrm{x}_{\mathrm{i}}$ holds a determined value.

$\beta_{i}=$ coefficients are representing each independent variable's contribution to the probability of success. Thus, $\beta_{i}=0$ would mean that independent explanatory variable $\mathrm{x}_{\mathrm{i}}$ did not contribute towards the likelihood of success.

The Wald test permits the construction of the final model from independent variables. According to (Vaeth, 1985), the Wald test enables us to determine whether an independent variable contributed towards the particular impact $\left(H_{1}\right)$. This test is associated with the following statistical hypothesis:

$$
H_{0}: \beta_{i}=0
$$

$$
H_{1}: \beta_{i} \neq 0
$$

The Wald test applies the following formula:

$$
w=\frac{\left(b_{i}-\beta_{i}\right)^{2}}{\operatorname{var}\left(b_{i}\right)}
$$

where:

$w=$ Chi-squared distribution with one degree of freedom.

$b_{i}=$ estimation of the variable coefficient utilising sample values. Regarding significance, the p-value less than $5 \%$ rejects Ho or accepts it for higher amounts.

The Wald test was applied iteratively until the parameters complied with the significance threshold.

\section{Results}

There are two categories of results. The first part characterises the companies and validates their uniformity and compliance with the conditions of the research. The results of the second part quantify the relationship and the impact of CI on BS.

\subsection{General Characteristics of the Companies}

Regarding the CI support structure, $55 \%$ of the participating companies stated that they were certified, with at least one of the leading certifications (ISO 9001, ISO 14001, OSHAS 18000) contributing to their company's CI culture (Figure 2). Based on the industry norms, the companies are categorised as 38\% small, 63\% medium, and 58\% large. Considerably, $7 \%$ of the medium and $12 \%$ of the large companies stated that they obtained all three principal certifications simultaneously.

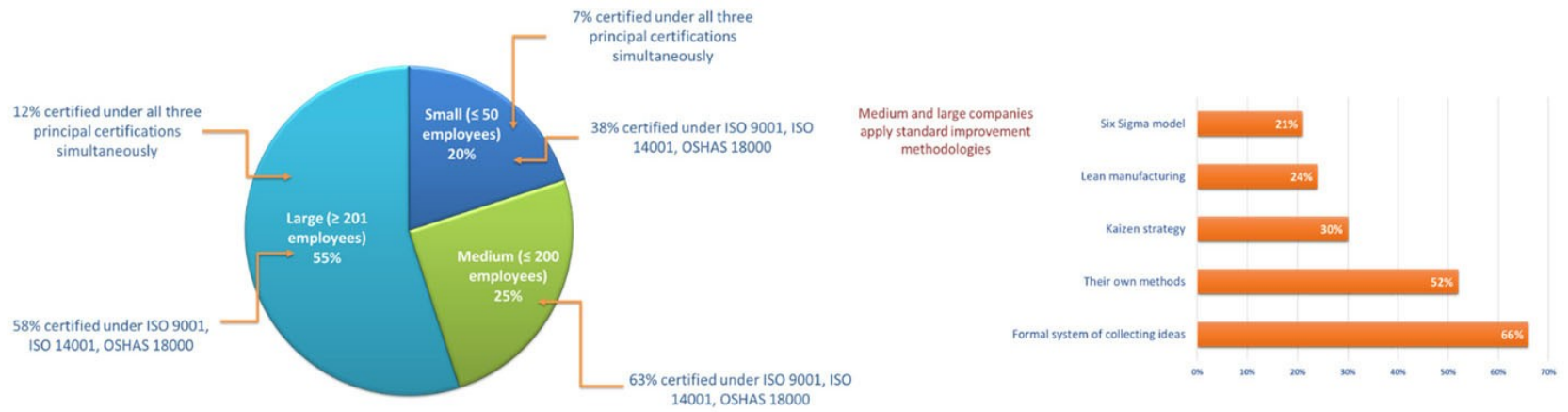

Figure 2. General Characteristics of the Companies 
Additionally, in terms of the methodology, medium and large companies apply standard improvement methodologies, from which, $66 \%$ adopted a formal system of collecting ideas; $52 \%$ developed their methods, $30 \%$ adapted the Kaizen strategy, 24\% used lean manufacturing, and 21\% adopted the Six Sigma model.

A total of $82 \%$ (16\% small, $23 \%$ medium, and $43 \%$ large) of the companies utilise permanent work teams with the same employees. Changing work teams are referred to as temporary improvement teams and were present in $41 \%$ of the companies (5\% small, $8 \%$ medium, and $28 \%$ large). As evident from the data, some companies embrace the combination of the two work team types.

Furthermore, $88 \%$ of the companies stated that they employed long-term CI actions or made small improvement changes over time (18\% small, $22 \%$ medium, and $48 \%$ large). A total of $41 \%$ stated that they exerted radical, significant, or innovative improvements (5\% small, $8 \%$ medium, and $28 \%$ large).

Finally, the survey indicates an increased impact of CI and companies' improved performance in the following aspects: financial (74\%), environmental (57\%), and social aspects (67\%). The most significant financial impact concerned improved profits (81\%) while the lowest impact affected reduced costs (74\%). The most significant impact on social aspects involved enhanced relationships with customers (82\%), and with a moderate impact regarding company relationships with state entities $(52 \%)$.

\subsection{Relationship Between CI Components and BS Dimensions}

Table 1 provides the results of the logistic regression model concerning each BS dimension. The four models evaluate each of dependent variable (i.e., each aspect related to BS concepts-social, environmental, financial, and operational). Demographic variables were not included in the adjusted models as preliminary analysis revealed that they had not contributed towards any type of impact.

\subsubsection{Impact on the Social Dimension}

Table 1 presents the result of logistic regression model for the variables related to improvement systems and work teams that have significant impact on the social dimension of companies ( $\mathrm{p}$-values $\leq 5 \%$ ). These variables are the percentage of managers in work teams, informative talks, and teamwork skills.

\begin{tabular}{|l|r|r|r|r|}
\hline & \multicolumn{1}{|c|}{ Coeff b } & \multicolumn{1}{c|}{ SE } & \multicolumn{1}{c|}{ Wald } & \multicolumn{1}{c|}{ p-value } \\
\hline Intercept & -4.842 & 1.148 & 17.790 & $0 \%$ \\
\hline B2.4 - \% managers in work teams & 1.040 & 0.561 & 3.437 & $4 \%$ \\
\hline B3.1 - Informative talks & 0.563 & 0.230 & 6.438 & $1 \%$ \\
\hline B3.3 - In teamwork skills & 0.696 & 0.206 & 11.349 & $0 \%$ \\
\hline
\end{tabular}

Table 1. Improvement system and work teams variables having a high impact on companies' social dimension

We obtain the following equation based on the variables that significantly influence social dimension:

$$
P(Y=1)=\frac{1}{1+e^{-(-4.842+B 2.4 * 1.04+B 3.1 * 0.563+B 3.3 * 0.696)}}
$$

\subsubsection{Impact on the Environmental Dimension}

Table 2 presents the result of logistic regression model for the variables related to improvement systems and work teams that have significant impact on the environmental dimension of companies ( $p$-values $\leq 5 \%$ ). These variables are the percentage of managers in work teams, Permanent radical improvement teams, External guide (consulting, external facilitator, etc.), Human talent for system maintenance, percentage of middle managers and technicians in work teams, percentage of managers in the team works, and working conditions and work environment. 


\begin{tabular}{|c|c|c|c|c|}
\hline & Coeff. b & SE & Wald & p-value \\
\hline Intercept & -9.112 & 1.926 & 22.392 & $0 \%$ \\
\hline A2.1 - \% of the people in work teams. & 1.439 & 0.585 & 6.042 & $1 \%$ \\
\hline A3.4.1 - Permanent radical improvement teams. & -0.447 & 0.1727 & 6.706 & $1 \%$ \\
\hline A4.3 - External guide (consulting, external facilitator, etc.). & 1.317 & 0.505 & 6.789 & $1 \%$ \\
\hline A5.2 - Human talent for system maintenance. & 1.249 & 0.346 & 13.011 & $0 \%$ \\
\hline B2.3 - \% middle managers and technicians in work teams. & 3.639 & 1.1146 & 10.661 & $0 \%$ \\
\hline B2.4 - \% managers in the team works. & -1.830 & 0.841 & 4.738 & $3 \%$ \\
\hline B4.5 - They are related to working conditions and work environment. & 1.115 & 0.269 & 17.202 & $0 \%$ \\
\hline
\end{tabular}

Table 2. Improvement system and work teams variables having a high impact on companies' environmental dimension

The logistic regression model, applying only the significant variables for the environmental dimension, is formed as follows:

$$
P(Y=1)=\frac{1}{1+e^{-(-9.112+A 2.1 * 1.439+A 3.4 .1 *-0.447+A 4.3 * 1.317+A 5.2 * 1.249+B 2.3 * 3.639+B 2.4 *-1.830+B 4.5 * 1.115)}}
$$

\subsubsection{Impact on the Operational Dimension}

Table 3 presents the result of logistic regression model for the variables related to improvement systems and work teams that have significant impact on the operational dimension of companies ( $\mathrm{p}$-values $\leq 5 \%$ ). These variables are statistical and quality management tools, and teamwork skills.

\begin{tabular}{|l|r|r|r|r|}
\hline & Coeff. b & SE & \multicolumn{1}{|c|}{ Wald } & p-value \\
\hline Intercept & -5.035 & 1.085 & 21.527 & $0 \%$ \\
\hline B3.2 - In statistical and quality management tools. & 0.870 & 0.212 & 16.870 & $0 \%$ \\
\hline B3.3 - In teamwork skills. & 0.798 & 0.229 & 12.067 & $0 \%$ \\
\hline
\end{tabular}

Table 3. Improvement system and work teams variables having a high impact on companies' operational dimension

The following equation adjusts a new logistic regression model that predicts the probability of high operational impact using only the variables in Table 3:

$$
P(Y=1)=\frac{1}{1+e^{-(-5.035+B 3.2 * 0.870+B 3.3 * 0.798)}}
$$

\subsubsection{Impact on the Financial Dimension}

Table 4 presents the result of logistic regression model for the variable related to improvement systems and work teams that have significant impact on the financial dimension of companies ( $p$-values $\leq 5 \%$ ). The variable is "The

\begin{tabular}{|c|c|c|c|c|}
\hline & Coeff. b & SE & Wald & p-value \\
\hline Intercept & -2.602 & 0.752 & 11.960 & $1 \%$ \\
\hline B5.4 - The proposals are implemented, their results are measured and standardized. & 1.001 & 0.212 & 22.321 & $0 \%$ \\
\hline
\end{tabular}
proposals are implemented, their results are measured and standardized".

Table 4. Variables regarding improvement system and work teams having a high impact on companies' financial dimension 
Using only significant variables, the logistic regression model for the financial dimension is as follows:

$$
P(Y=1)=\frac{1}{1+e^{-(-2.602+B 5.4 * 1.001)}}
$$

Figure 3 presents an overview of the obtained results of critical factors of CI (systems and work teams) that impact BS significantly.

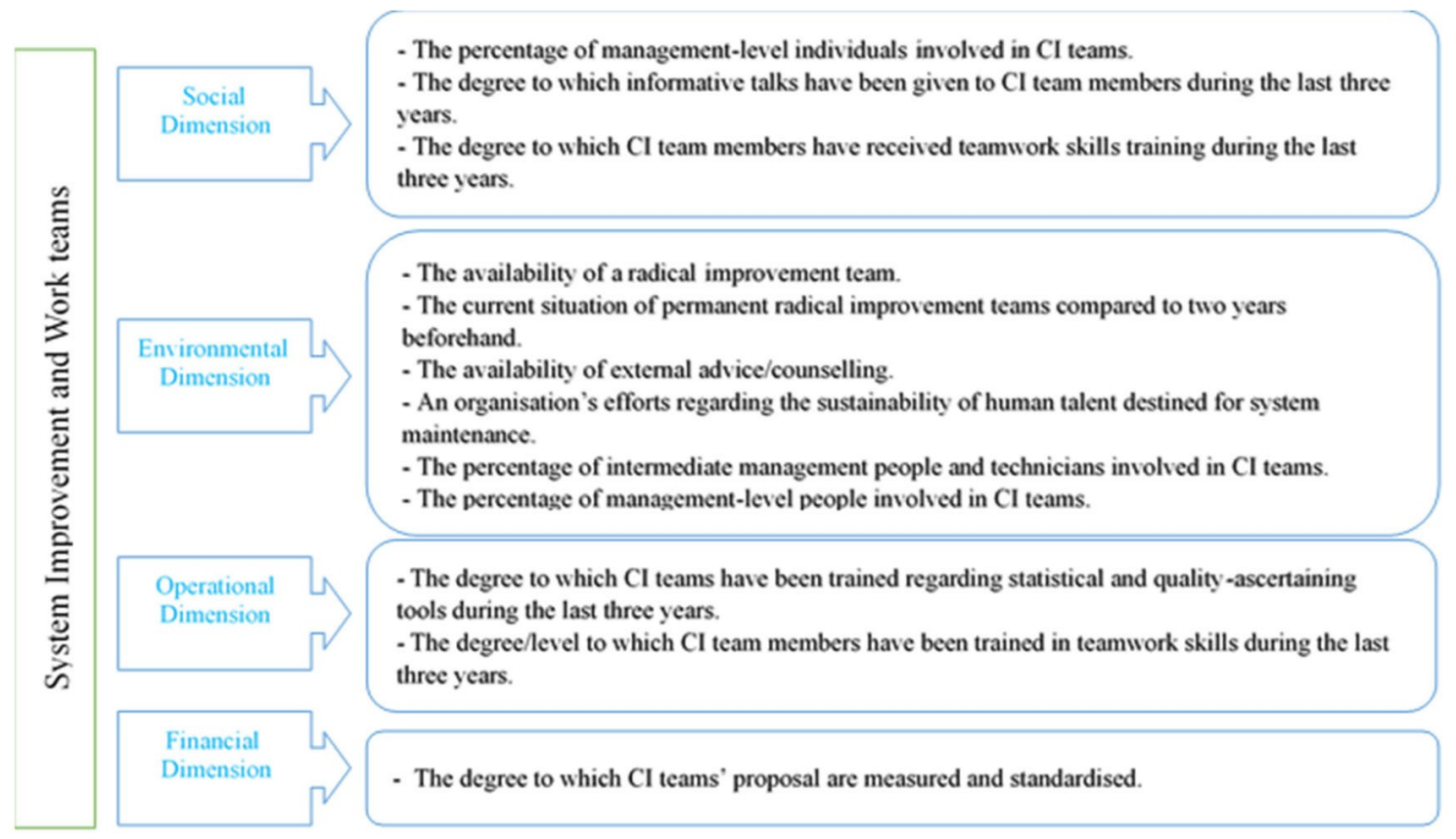

Figure 3. Key factors of continuous improvement

\section{Discussion}

In this section, we provide a presentation of different aspects of the relation between CI and BS in emerging markets.

The past research indicates that CI and BS are vital factors for business activities in developing countries regardless of distances in socio-demographic variables such as size, sector of economic activity, years of operation and legal nature of companies (Pojasek, 2007; Mårtensson et al., 2019; Garza-Reyes, Rocha-Lona \& Kumar, 2014; Meza-Ruiz et al., 2017; Mårtensson et al., 2019; Nigri \& Baldo, 2018). The results of the current study confirm that CI systems and work teams positively impact each of the BS dimensions in Colombian companies.

Additionally, the previous research indicates that companies should ensure a balance between different BS dimensions, obtaining financial results, operational activity, and social and environmental impact, because the stakeholders are becoming more demanding of this balance (Bingol \& Polat, 2017; Rezaee, 2016). The results of the research indicate that participating companies give high priority to the financial and operational aspects by spending more on risk management and ability to adapt to change to avoid debt rather than responding to environmental and social aspects. These results contrast with the status quo of BS in advanced economies which emphasise on efficient resources usage, social inclusivity, and environmental protection without compromising profitability in any way (Unerman, Bebbington \& O’Dwyer, 2007; Schaltegger, 2010; Delai \& Takahashi, 2013).

The results also highlight the fact that international standards (ISO 9001, ISO 14001, OSHAS 18000) has little impact on BS in emerging economies, which is in contrast with the results of Hahn and Kühnen (2013) and Barkemeyer, Preuss \& Lee (2015). In emerging economies, most of the companies are small or medium size, informal and with limited financial resources that make it difficult to expect them to spend on the standards or oblige them to report their activities to comply with government regulations. However, as results show, better social 
conditions in the CI system and work teams can lead to more social and environmental responsibility of these businesses without putting them at financial risks.

The results show that in emerging markets, focusing on the CI system and work teams can maximise internal social via employee training and engagement and external social impact by providing better general conditions for the employees. CI investment in emerging economies has a higher impact on the social aspect rather than on environmental issues.

Human resource management strategies applied in CI methodologies can minimise the effect of corruption on different levels of business activities and the external effects by motivating employees and providing them more trust and better work environment and as a result employee commitment. These results coincide with the strategies by Silvestre (2015) to solve problems regarding corruption and social responsibility.

The main reason that companies in the emerging market fall behind in terms of sustainability (Delai \& Takahashi, 2013) is mainly due to excessive debt, and primarily ignored social aspects of sustainability such as the lack of the legal framework, societal infrastructure, or established traditions and experience of developed countries. The fast urbanisation and rising standards of living impact environmental health and increase social stratification.

From 70 survey items evaluated applying logistic regression models (improvement system and work teams), only 13 items (grouped into four categories) significantly contribute to BS. These categories are employee involvement, human talent maintenance, training, and evaluation accompanied by feedback (Figure 4). The 11 of 13 items are related to the human conduct necessary to assure the success of CI and consequently, companies' BS achievement. These results confirm the importance of human action in CI and therefore, in BS are aligned with the BS success factors identified by Paipa-Galeano et al. (2020) in emerging markets and Nguyen and Robinson (2015), Shub and Stonebraker (2009) and Seuring and Gold (2012) in advanced economies.

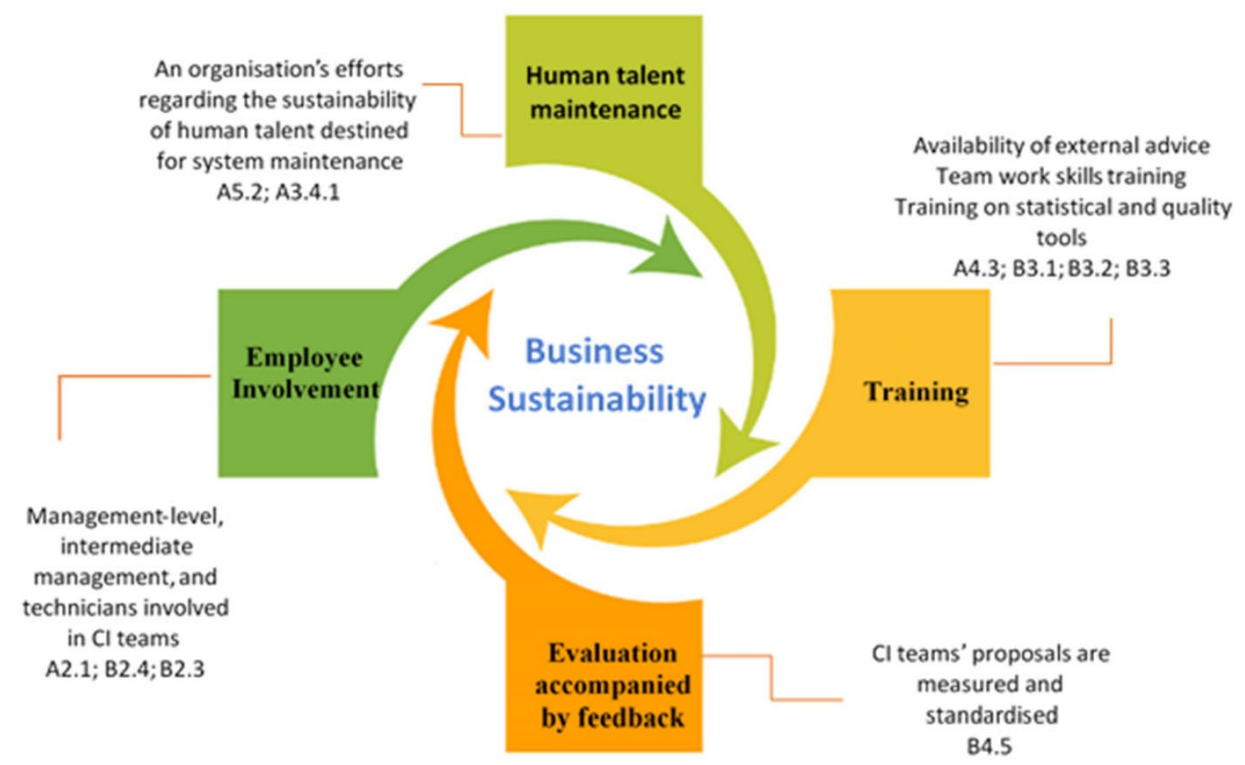

Figure 4. Categories of the key factors of continuous improvement and business sustainability

\section{Conclusions}

Companies, to compete in the modern business environment, are looking for strategies that guaranty their improvement and competitiveness in the turbulent markets of emerging economies. The limitations, such as increased social problems, insufficient government support, investment, and infrastructure result in emerging markets companies falling behind their sustainability promises in comparison to their counterparts in developed economies. The specific context of emerging economies demands crafted strategies to align solutions to the problems facing companies and society. The results of the study provide empirical support in the companies of 
emerging economies in the importance of improvement system and work teams as crucial factors to achieve business excellence and as a result BS by creating value for all the stakeholders. The significance of this study is to differentiate between the business contexts of emerging and developed economies to provide an alternative guide for the companies that uncritically apply experiences of management models created and tested in companies in developed countries.

The results provide evidence to confirm the impact of CI systems and work teams on each BS dimension in emerging markets and specify four key categories that make a significant contribution to BS. These categories are employee involvement, human talent maintenance, training, and evaluation accompanied by feedback. Besides, the results indicate that an adequate strategy in CI systems and work teams can significantly impact the BS social dimension.

This paper contributes to the theory by conducting an empirical study to add to the understanding of the relation between CI (systems and teams) and BS in the context of emerging economies. Also, the results support the importance of the evolution from CI, particularly the vital role of human resources, to business excellence and consequently to BS in emerging economies. Equally, the outcomes contribute to the understanding of organisations internal and external environment and the effectiveness of their systems and continuous improvement teams concerning BS. Also, BS dimensions should not be restricted only to the economic, social, and environmental aspects, but also to the operational aspect which is directly related to the production process. In addition, BS contributes to the care of natural resources, social development with economic benefit for the investors. However, the prior research indicates that environment continues to deteriorate no matter how companies increasingly adopt sustainability standards. The lack of a stronger concept based on concern for the environment in micro and macro level is the reason for this phenomenon (Dyllick \& Muff, 2016; Landrum, 2018).

From a practical point of view, the results of the current research are a valuable source of information for strategic decision-making by entrepreneurs, managers, business associations, consultants and those responsible in government entities for seeking business competitiveness applying CI.

Another practical contribution consists of providing a guide that generates overall awareness toward the importance of the equilibrium of sustainability dimensions in strategic planning and implementation in the companies in the emerging economies. Notably, the current research identifies the four main categories of employee involvement, human talent maintenance, training, and evaluation accompanied by the feedback that improve social inequality by promoting education, training and feedback. Employee involvement and awareness leads to transparency in the operations. Employee training and care improves the overall informal businesses that try to avoid compliance with the established norms.

Since the current research is limited to the general sustainability analysis in Colombia and specifically Bogota city, future research should focus on in-depth multiple case studies of companies in various emerging economies focusing on environmental aspect with a systematic vision that integrates micro and macro level contributors. Team members are the vital element that impacts team consolidation, and it is necessary to include their characteristics in future studies. Additionally, future research can describe the relationship between the size of improvement teams and sustainability for companies in specific sectors of economic activity.

\section{Declaration of Conflicting Interests}

The authors declared no potential conflicts of interest with respect to the research, authorship, and/or publication of this article.

\section{Funding}

The authors received no financial support for the research, authorship, and/or publication of this article.

\section{References}

Abbas, J. (2020). Impact of total quality management on corporate sustainability through the mediating effect of knowledge management. Journal of Cleaner Production, 244, 118806. https://doi.org/10.1016/j.jclepro.2019.118806 
Barkemeyer, R., Preuss, L., \& Lee, L. (2015). On the effectiveness of private transnational governance regimes Evaluating corporate sustainability reporting according to the Global Reporting Initiative. Journal of World Business, 50(2), 312-325. https://doi.org/10.1016/J.JWB.2014.10.008

Bernal, C.A., Amaya, N., Gaviria-Peñaranda, A., \& Zwerg-Villegas, A.M. (2020). Knowledge and organisational performance in franchised restaurants in Colombia. International Journal of Emerging Markets. https://doi.org/10.1108/IJOEM-04-2019-0322

Bessant, J., Caffyn, S., \& Gallagher, M. (2001). An evolutionary model of continuous improvement behaviour. Technovation, 21(2), 67-77. https:// doi.org/10.1016/S0166-4972(00)00023-7

Bingol, B.N., \& Polat, G. (2017). Measuring Managerial Capability of Subcontractors Using a KPI Model. Procedia Engineering, 196, 68-75. https://doi.org/10.1016/j.proeng.2017.07.174

Bortagaray, I., \& de Montevideo, U.O. (2016). Politicas de Ciencia, Tecnología, e Innovación Sustentable e Inclusiva en América Latina. Cilac, Unesco. Available at: http://www.unesco.org/new/fileadmin/MULTIMEDIA/FIELD/Montevideo/pdf/PolicyPapersCILACInnovacionEmpresarial.pdf

Boulter, L., Bendell, T., \& Dahlgaard, J. (2013). Total quality beyond North America. International Journal of Operations \& Production Management, 33(2), 197-215. https://doi.org/10.1108/01443571311295635

Chang, R.D., Zuo, J., Zhao, Z.-Y., Zillante, G., Gan, X.L., \& Soebarto, V. (2017). Evolving theories of sustainability and firms: History, future directions and implications for renewable energy research. Renewable and Sustainable Energy Reviews, 72, 48-56. https://doi.org/10.1016/j.rser.2017.01.029

Conti, R., Angelis, J., Cooper, C., Faragher, B., \& Gill, C. (2006). The effects of lean production on worker stress. International Journal of Operations and Production Management, 26(9), 1013-1038. https://doi.org/10.1108/01443570610682616

Corrales-Estrada, A.M., Gómez-Santos, L.L., Bernal-Torres, C.A., \& Rodriguez-López, J.E. (2021). Sustainability and Resilience Organizational Capabilities to Enhance Business Continuity Management: A Literature Review. Sustainability, 13(15), 8196. https://doi.org/10.3390/su13158196

Creasey, S. (2007). How going green helps you clean up. Printing Worl, 66-68.

Daily, B.F., Bishop, J.W., \& Massoud, J.A. (2012). The role of training and empowerment in environmental performance: A study of the Mexican maquiladora industry. International Journal of Operations and Production Management, 32(5), 631-647. https://doi.org /10.1108/01443571211226524

Del Brío, J.Á., Fernandez, E., \& Junquera, B. (2007). Management and employee involvement in achieving an environmental action-based competitive advantage: An empirical study. The International Journal of Human Resource Management, 18(4), 491-522. https://doi.org/10.1080/09585190601178687

Delai, I., \& Takahashi, S. (2013). Corporate sustainability in emerging markets: insights from the practices reported by the Brazilian retailers. Journal of Cleaner Production, 47, 211-221. https://doi.org/10.1016/j.jclepro.2012.12.029

Dyllick, T., \& Muff, K. (2016). Clarifying the meaning of sustainable business: Introducing a typology from business-as-usual to true business sustainability. Organization \& Environment, 29, 156-174.

https://doi.org/10.1177/1086026615575176

Fernando, Y., Jabbour, C.J.C., \& Wah, W.X. (2019). Pursuing green growth in technology firms through the connections between environmental innovation and sustainable business performance: does service capability matter? Resources, Conservation and Recycling, Written paper, 141, 8-20. Available at: https://agris.fao.org/agris-search/search.do?recordID=US201900023582 https://doi.org/10.1016/j.resconrec.2018.09.031

Formento, H.R., Chiodi, F.J, Cusolito, F.J., Altube, L.A. \& Gatti, S.P. (2013). Key factors for a continuous improvement process. Independent Journal of Management and Production, 4(2), 391-415. Available at: https://dialnet.unirioja.es/servlet/articulo?codigo $=5680248$ https://doi.org/10.14807/ijmp.v4i2.76 
García-Alcaraz, J.L., Flor-Montalvo, F., Avelar-Sosa, L., Sánchez-Ramírez, C., \& Jiménez-Macias, E. (2019). Human Resource Abilities and Skills in TQM for Sustainable Enterprises. Sustainability, 11, 6488, 1-22.

https://doi.org/10.3390/su11226488

García-Arca, J., \& Prado-Prado, J.C. (2011). Systematic personnel participation for logistics improvement: A case study. Human Factors and Ergonomics in Manufacturing \& Service Industries, 21(2), 209-223.

https://doi.org/10.1002/hfm.20246

Garza-Reyes, J.A., Rocha-Lona, L., \& Kumar, V. (2015). A conceptual framework for the implementation of quality management systems. Total Quality Management \& Business Excellence, 26(11-12), 1298-1310.

https://doi.org/10.1080/14783363.2014.929254

George, D., \& Mallery, P. (2010). SPSS for Windows Step by Step: A Simple Guide and Reference 18.0 Update (11th ed.). Prentice-Hall.

González-Aleu, F., \& Van Aken, E. (2016). Systematic literature review of critical success factors for continuous improvement projects. International Journal of Lean Six Sigma, 7(3), 214-232. https://doi.org/10.1108/IJLSS-06-20150025

Gölgeci, I., Assadinia, S., Kuivalainen, O., \& Larimo, J. (2019). Emerging-market firms' dynamic capabilities and international performance: The moderating role of institutional development and distance. International Business Review, 28(6), 101593. https://doi.org/10.1016/j.ibusrev.2019.101593

Granerud, L., \& Rocha, R.S. (2011). Organisational learning and continuous improvement of health and safety in certified manufacturers. Safety Science, 49, 1030-1039. https://doi.org/10.1016/j.ssci.2011.01.009

Hahn, R., \& Kühnen, M. (2013). Determinants of sustainability reporting: a review of results, trends, theory, and opportunities in an expanding field of research. Journal of Cleaner Production, 59, 5-21. https://doi.org/10.1016/J.JCLEPRO.2013.07.005

Hasle, P., Bojesen, A., Jensen, P.L., \& Bramming, P. (2012). Lean and the working environment: A review of the literature. International Journal of Operations \& Production Management, 32(7), 829-849. https://doi.org/10.1108/01443571211250103

Jaca, C., Suárez-Barraza, M.F., Viles-Díez, E., Mateo-Dueñas, R., \& Santos-García, J. (2011). Encuesta de sostenibilidad de sistemas de mejora continua: Comparativa de dos comunidades industriales de España y México. Intangible Capital, 7(1), 143-169. https://doi.org/10.3926/ic.2011.v7n1.p143-169

Jayanti, R.K., \& Gowda, M.R. (2014). Sustainability dilemmas in emerging economies. IIMB Management Review, 26(2), 130-142. https://doi.org/10.1016/j.iimb.2014.03.004

Jurburg, D., Viles, E., Tanco, M., \& Mateo, R. (2018). Continuous improvement leaders, followers and laggards: understanding system sustainability. Total Quality Management \& Business Excellence, 29(7-8), 817-833. https://doi.org/10.1080/14783363.2016.1240610

Lacy, P., \& Hayward, R. (2011). A new era of sustainability in emerging markets? Insights from a global CEO study by the United Nations Global Compact and Accenture, Corporate Governance. International Journal of Business in Society, 11(4), 348-357. https://doi.org/10.1108/14720701111159208

Landrum, N.E. (2018). Stages of corporate sustainability: Integrating the strong sustainability worldview. Organization \& Environment, 31(4), 287-313. https:/ / doi.org/10.1177/1086026617717456

Liao, S., Chen, Y.J., \& Deng, M. (2010). Mining customer knowledge for tourism new product development and customer relationship management. Expert Systems with Applications, 37(6), 4212-4223. https://doi.org/10.1016/J.ESWA.2009.11.081

Liu, H., Wu, S., Zhong, C., \& Liu, Y. (2020). The Sustainable Effect of Operational Performance on Financial Benefits: Evidence from Chinese Quality Awards Winners. Sustainability, 12(5), 1966.

https://doi.org/10.3390/su12051966 
Longoni, A., Golini, R., \& Cagliano, R. (2014). The role of new forms of work organisation in developing sustainability strategies in operations. International Journal of Production Economics, 147, 147-160.

https://doi.org/10.1016/j.ijpe.2013.09.009

López, M., Hernández, A., \& Marulanda, C.E. (2014). Procesos y Prácticas de Gestión del Conocimiento en Cadenas Productivas de Colombia. Información Tecnológica, 25(3), 125-134. https://doi.org/10.4067/S0718-07642014000300015

Mani, V., Gunasekaran, A., \& Delgado, C. (2018). Enhancing supply chain performance through supplier social sustainability: An emerging economy perspective. International Journal of Production Economics, 195, $259-272$. https://doi.org/10.1016/j.ijpe.2017.10.025

Mårtensson, A., Snyder, K., \& Ingelsson, P. (2019). Interlinking Lean and sustainability: how ready are leaders?. The TQM Journal, 31(2), 136-149. https://doi.org/10.1108/TQM-04-2018-0046

Marín-García, J.A., \& Bautista-Poveda, Y. (2010). The implementation of a continuous improvement project at a Spanish marketing company: A case study. International Journal of Management, 27(3), 593-606.

Marin-Garcia, J.A., \& Bonavia, T. (2014). Relationship between employee involvement and lean manufacturing and its effect on performance in the rigid continuous process industry. International Journal of Production Research, 53(11), 3260-3275. https://doi.org/10.1080/00207543.2014.975852

Martins, N.O. (2016). Ecosystems, strong sustainability and the classical circular economy. Ecological Economics, 129, 32-39. https://doi.org/10.1016/j.ecolecon.2016.06.003

Medne, A., \& Lapina, I. (2019). Sustainability and Continuous Improvement of Organisation: Review of ProcessOriented Performance Indicators. Journal of Open Innovation: Technology, Market, and Complexity, 5(3), 49. https://doi.org/10.3390/joitmc5030049

Meza-Ruiz, I.D., Rocha-Lona, L., Soto-Flores, M.R., Garza-Reyes, J.A., Kumar, V., \& López-Torres, G.C. (2019). Measuring business sustainability maturity-levels and best practices. Procedia Manufacturing, 11, 751-759. https://doi.org/10.1016/j.promfg.2017.07.176

Mohrman, S.A., \& Worley, C.G. (2010). The organisational sustainability journey: Introduction to the special issue. Organizational Dynamics, 39(4), 289-294. https://doi.org/10.1016/j.orgdyn.2010.07.008

Muñoz-Villamizar, A., Santos, J., Viles, E., \& Ormazábal, M. (2018). Manufacturing and environmental practices in the Spanish context. Journal of Cleaner Production, 178, 268-275. https://doi.org/10.1016/j.jclepro.2018.01.026

Neri, A., Cagno, E., Di Sebastiano, G., \& Trianni, A. (2018). Industrial sustainability: Modelling drivers and mechanisms with barriers. Journal of Cleaner Production, 194, 452-472. https://doi.org/10.1016/j.jclepro.2018.05.140

Nguyen, P.A., \& Robinson, A.G. (2015). Continuous improvement in Vietnam: unique approaches for a unique culture. Journal of Asia Business Studies, 9(2), 195-211. https://doi.org/10.1108/JABS-11-2014-0093

Nigri, G., \& Del Baldo, M. (2018). Sustainability Reporting and Performance Measurement Systems: How Do Small and Medium-Sized Benefit Corporations Manage Integration? Sustainability, 10(12), 4499.

https://doi.org/10.3390/su10124499

Oliveira Neto, G.C., Pinto, L.F.R., Amorim, M.P.C., Giannetti, B.F., \& Almeida, C.M.V.B. (2018). A framework of actions for strong sustainability. Journal Cleaner Production, 196, 1629-1643.

https://doi.org/10.1016/j.jclepro.2018.06.067

Paipa-Galeano, L., Bernal-Torres, C.A., Otálora, L.M.A., Jarrah Nezhad, Y., \& González-Blanco, H.A. (2020). Key lessons to maintain continuous improvement: A case study of four companies. Journal of Industrial Engineering and Management, 13(1), 195-211. https://doi.org/10.3926/jiem.2973

Pinto, L.F.R., Venturini, G.D.F.P., Digiesi, S., Facchini, F., \& Oliveira Neto, G.C.D. (2020). Sustainability assessment in manufacturing under a strong sustainability perspective - An ecological neutrality initiative. Sustainability, 12(21), 9232. https://doi.org/10.3390/su12219232 
Pojasek, R.B. (2007). A framework for business sustainability. Environmental Quality Management, $17(2), 81$. https://doi.org/10.1002/tqem.20168

Ranganathan, P., Pramesh, C.S., \& Aggarwal, R. (2017). Common pitfalls in statistical analysis: Logistic regression. Perspectives in Clinical Research, 8(3), 148-151. https://doi.org/10.4103/picr.PICR_87_17

Rezaee, Z. (2016). Business sustainability research: A theoretical and integrated perspective. Journal of Accounting Literature, 36, 48-64. https://doi.org/10.1016/j.acclit.2016.05.003

Sabella, A., Kashou, R., \& Omran, O. (2014). Quality management practices and their relationship to organisational performance. International Journal of Operations \& Production, 34, 1487-1505. https://doi.org/10.1108/IJOPM-04-20130210

Sanchez, L., \& Blanco, B. (2014). Three decades of continuous improvement. Total Quality Management \& Business Excellence, 25(9-10), 986-1001. https://doi.org/10.1080/14783363.2013.856547

Schaltegger, S. (2010). Sustainability as a Driver for Corporate Economic Success Consequences for the Development of Sustainability Management Control. Society and Economy, 33(1), 15-28. https://doi.org/10.1556/SocEc.33.2011.1.4

Schroeder, D.E., \& Robinson, A.G., (2010). Creating sustainable competitive advantage through green excellence. Organizational Dynamics, 39(4), 345-352. https://doi.org/10.1016/j.orgdyn.2010.07.002

Seuring, S., \& Gold, S. (2012). Conducting content-analysis based literature reviews in supply chain management. Supply Chain Management: An International Journal, 17(5), 544-555. https://doi.org/10.1108/13598541211258609

Sheth, J.N., \& Sinha, M. (2015). B2B branding in emerging markets: A sustainability perspective. Industrial Marketing Management, 51, 79-88. https://doi.org/10.1016/j.indmarman.2015.06.002

Shub, A.N., \& Stonebraker, P.W. (2009). The human impact on supply chains: evaluating the importance of "soft" areas on integration and performance. Supply Chain Management: An International Journal, 14(1), 31-40. https://doi.org/10.1108/13598540910927287

Silvestre, B.S. (2015). Sustainable supply chain management in emerging economies: Environmental turbulence, institutional voids and sustainability trajectories. International Journal of Production Economics, 167, 156-169. https://doi.org/10.1016/j.ijpe.2015.05.025

Silvestre, B.S., \& T, Tîrcă, D.M. (2019). Innovations for sustainable development: Moving toward a sustainable future. Journal of Cleaner Production, 208, 325-332. https://doi.org/10.1016/j.jclepro.2018.09.244

Steurer, R. (2010). The role of governments in corporate social responsibility: Characterising public policies on CSR in Europe. Policy Sciences, 43(1), 49-72. https://doi.org/10.1007/s11077-009-9084-4

Taddeo, R., Simboli, A., Di Vincenzo, F., \& Ioppolo, G. (2019). A bibliometric and network analysis of Lean and Clean(er) production research (1990/2017). Science of the Total Environment, 653, 765-775.

https://doi.org/10.1016/j.scitotenv.2018.10.412

Teixeira, A.A., Jabbour, C.J.C., \& Jabbour, A.B.L. (2012). Relationship between green management and environmental training in companies located in Brazil: a theoretical framework and case studies. International Journal of Production Economics, 140, 318-329. https://doi.org/10.1016/j.ijpe.2012.01.009

Treacy, R., Humphreys, P., McIvor, R., \& Lo, C.K.Y. (2019). ISO14001 certification and operating performance: A practice-based view. International Journal of Production Economics, 208, 319-328.

https://doi.org/10.1016/j.ijpe.2018.12.012

Unerman, J., Bebbington, J., \& O’Dwyer, B. (2007). Sustainability accounting and accountability. New York: Routledge.

Vaeth, M. (1985). On the Use of Wald's Test in Exponential Families. International Statistical Review / Revue Internationale de Statistique, 53(2), 199. https://doi.org/10.2307/1402935 
Vicente, S., Alves, A.C., Carvalho, S.M., \& Costa, N. (2015). Business sustainability through employees involvement: a case study. FME Transactions, 43(4), 362-369. https://doi.org/10.5937/fmet1504362V

Welch, S., \& Comer, J. (1988). Quantitative Methods for Public Administration: Techniques and Applications. Journal of Policy Analysis and Management, 2(4), 655-656. https://doi.org/10.2307/3323621

Journal of Industrial Engineering and Management, 2021 (www.jiem.org)

\section{(c) (1) $(9)$}

Article's contents are provided on an Attribution-Non Commercial 4.0 Creative commons International License. Readers are allowed to copy, distribute and communicate article's contents, provided the author's and Journal of Industrial Engineering and Management's names are included. It must not be used for commercial purposes. To see the complete license contents, please visit https://creativecommons.org/licenses/by-nc/4.0/. 